\title{
Effect of the Passage for Different Tractors on the Soil Compaction
}

\author{
Anis Elaoud ${ }^{1,2^{*}}$, Sayed Chehaibi ${ }^{1}$ and Khaoula Abrougui ${ }^{1}$ \\ ${ }^{1}$ Higher Institute of Agronomy Chott-Mariem 4042 Sousse (Tunisia) \\ ${ }^{2}$ Higher Engineering School for Rural Equipment Medjez Elbeb (Tunisia) \\ Accepted 10 Feb 2015, Available online 20 Feb 2015, Vol.5, No.1 (Feb 2015)
}

\begin{abstract}
Soil compaction is a serious problem in agriculture. This compression is caused by the passage of machinery on soils, particularly in conditions of excess moisture. At regional level, we studied the influence of the weight of two different tractors on soil failure and compaction. The experimental parts which are based on the passage of two types of tractors, (a small tractor KUBOTA: engine power $25 \mathrm{~kW}$, type E-TCVS and $1200 \mathrm{~kg}$ and a means tractor: MATER 7007: $45 \mathrm{~kW}$ power, and weight $1900 \mathrm{~kg}$ ), are performed to quantify compaction caused by these types of equipment with inflation pressure of wheels 2bars. The study of resistance to penetration is produced on three soils worked uncultivated. This study showed an increased resistance to penetration by increasing the weight of the tractor. We increased the weight of the vehicle which realizes his passage on an agricultural soil of $38 \%$, an increase of accentuation and soil compaction can be up to $30 \%$ at the first parcel (P1) and $15 \%$ in the second parcel (P2) (eg 20 $\mathrm{cm}$ depth).And the number of passage, we note that the first pass of the tractor 1 effects an increased resistance to penetration by $44 \%$ compared to the initial state (passage 0) and the second pass makes a accentuation of $11 \%$ relative to the first pass at the parcel $P 2$, which shows that the first pass performs compaction most important and most severe. Thus, after a sometimes (eg 20 days) we notice that there's in decrease compaction can sometimes attain $62 \%$ (parcel 1 to $20 \mathrm{~cm}$ ) which shows that the ground based on the area and compaction in decrease function of time.
\end{abstract}

Keywords: Wheel traffic, Tractor, Soil compaction, Resistance to penetration.

\section{Introduction}

Compaction is due to the mechanization of agricultural activity. It implies passages of machines heavier during agricultural operations. Thus, the practicability of a soil reflects its ability to accept the passage of machines $(0$. Vitlox et al., 2002). Overuse of machinery and improper management led to soils compaction.

For many years, the trend in agriculture has been for increasing tractor size and weight, which increases the risk of severe soil compaction. The increasing engine size of the tractors also amplifies the demands on transferring power from the engine to draught force, i.e. using tyre equipment or tracks that can utilise the increasing engine power (M. Pagliai et al., 2003).

Soil compaction by wheeled agricultural vehicles has a negative impact on the structure of arable soils and in severe ways, it will affect crop production in both the short term and long term (B. Soane, 1994).

The vehicles, and the magnitude and distribution of their contact pressures at the soil surface directly affect the topsoil and its substrata. Soil compaction due to field machinery traffic is observed at the depth, which

*Corresponding author: Anis Elaoud is the cumulative effect of deformation beneath the surface (A. Abou-Zied et al., 2004). Accordingly, it is important to control the mechanical impact of the farm machinery structure of the soil, order to reduce soil settlement.

Because of soil compaction, the soil properties are altered, and a reduction in soil water and roots can occur (T. Batey, 2009)

In Tunisia, the agriculture sector has resorted to crop intensification through irrigation systems. These systems offer the possibility of greater diversification and intensification is consistent with the use of machinery (L. Hakansson et al, 1988 ; FAO, 2001). It can increase yields productivity, especially when it is well suited to local conditions (P. Bonnefond, 1970). But the intensively cultivated farming practices carried out over short periods of time when the soil is moist frequently. This results in higher sensitivity to of soil compaction which is persistent and cumulative.

Experimentally, a minority of the study was performed in Tunisia, specifically in the area of Chott Mariem (S. Chehaibi et al., 2006; S. Chehaibi et al., 2008). Therefore, this work was designed to study the effect of weight of the tractor and the influence of number of passage, since these two parameters may 
determine the degree of soil compaction (A. Elaoud et al., 2011; G.S.V. Raghavan et al., 1979; G.F. Botta, 2009).

\section{Materials and Methods}

\subsection{Experimental site and soil}

The farm investigation site was located at SousseTunisia $\left(35^{\circ} \mathrm{S}, 10^{\circ} \mathrm{N}\right)$. This is a research station of the Higher Institute of Science Agronomic - Chott Mariem. Soil textures were presented in table 1.

\subsection{Experimental plans}

In this study, an assessment of the impact of the change in weight of the tractor and the multiplication of passages was performed. The initial state of the soil moisture was characterized by measuring the water content in soil. Thus, the parameter measurements were made compaction to characterize the state of the ground just before and after each passage of the machine. Moreover, this operation was repeated every 20 days to characterize the evolution of soil compaction over time.

\subsection{Experimental device}

An experimental device was set to evaluate settlements feet related to expenses in the soil profile of agricultural land. The research processes, results and deficiencies associated with soil-machine components including evaluation of the soil. So the objective of our research is to study the structural changes of soil produced by the passage of tractors (with different weights) and the study of the impact of the number of passages. Thus, the evolution of the state of soil compaction was monitored over time.

The experimental study is based on the variation of three parameters. The first parameter is to change the weight of Tractor (tractor 1 (T1) and tractor 2 (T2)), with a wheel inflation pressure of 2 bars. The second parameter studied was the passage number (zero passage (P0), one passage (P1) and two passages (P2)). The third parameter is the time.

Thus, measures concerned the resistance to penetration profile and water content.

\subsection{Experimental conditions}

The tests were conducted in the area of the Higher Institute of Agronomy, Chott Mariem, Tunisia.

Table 1: Medium grain size in P1, P2 and P3

\begin{tabular}{|c|c|c|c|}
\hline Depth, cm & Clay, \% & Silt, \% & Sand, \% \\
\hline \multicolumn{4}{|c|}{ P1 } \\
\hline $0-10$ & 15.1 & 9.8 & 75.1 \\
\hline $10-20$ & 15.3 & 8.7 & 76 \\
\hline \multicolumn{4}{|c|}{ P2 } \\
\hline $0-10$ & 7 & 6.9 & 86.1 \\
\hline $10-20$ & 7.2 & 6.1 & 86.7 \\
\hline \multicolumn{4}{|c|}{ P3 } \\
\hline $0-10$ & 14.9 & 9.1 & 75.1 \\
\hline $10-20$ & 15.1 & 8.2 & 76.7 \\
\hline
\end{tabular}

This parcel of land is characterized by a sandy clay soil (table 1). The experimental devices have been adopted for the three treatments and three replications at the 3 plot level.

\subsection{Engine}

The type of tractor used on our experiences: Kubota L3430, what was the weight $1200 \mathrm{~kg}$ - this is very important, engine power $25 \mathrm{~kW}$. The size of the wheel front / rear: 7-16 / 12.4-24.

Matter 7007, what was the weight $1900 \mathrm{~kg}$, engine power $45 \mathrm{~kW}$. The size of the wheel front / rear: 7-16 / 12.4-24.

\subsection{Measurement of penetration resistance}

Soil penetration resistance is an important mechanical property that can be used as an indicator of soil compaction and it is important in determining the least limiting water range. In this study, the penetrometer was used, to measure soil mechanical resistance in the field (0. Vitlox, 1998). Soil resistance to penetration of a point is an indicator of the state of compaction and its evolution over time. It is a complex function of parameters characterizing the state of a ground such as cohesion, angle of internal friction and friction metal underground. These parameters are dependent on water content and soil texture. Measures the state of soil compaction using the penetrometer must be accompanied by measures of its water content near the points of measurement (J.F. Billot et al. 1993). Different types of penetrometers have been developed to measure soil penetrability (AG. Bengough et al., 2001; B. Lowery et al., 2002) that operate on static or dynamic principles. The static penetrometer is pushed into the soil at a constant rate, while the dynamic penetrometer is driven into the soil by repeated hammer-blows (used mainly in civil engineering), (JE. Herrick et al., 2002) described a dynamic penetrometer for use in soil science, enabling cheap, repeatable soil strength assessments in the field. The penetrometer model that we used for measurements of soil resistance to penetration in the different treatments is dynamic penetrometer (penetrologger). This is penetrologger has been especially developed to measure the resistance to penetration of the soil and to save the measuring results to digitally process them on a computer. The penetrologger is ergonomically designed, lightweight and easy to use. The penetrologger is available as a complete set suitable for measurements up to a depth of $80 \mathrm{~cm}$. The set consists of the penetrologger, cones, cone check, probing rod, a depth reference plate, a set of tools, a battery charger, a cable, software and a test report.

During the first experimental year (2013), penetration resistance of the soil under the wheel tracks, between the wheel tracks, as well as on an adjacent un-ripped area, was measured in area tillage and not cultivate after each traffic tractor using a 
penetrometer, a cone angle of $30^{\circ}$ and base of $10 \mathrm{~mm}$ (area $3.2 \mathrm{~cm}^{2}$ ).

\subsection{Measuring soil moisture}

The variation of the penetration depends on soil moisture (C. Kai, 2008). To this end, measures the resistance to penetration were carried out with monitoring of profiles of water content by weight at each treatment by the following method:

- Samples were taken every $10 \mathrm{~cm}$ to a depth of $20 \mathrm{~cm}$, the sampling is performed using a hand auger;

- The wet sample is weighed, or $\mathrm{P}_{\mathrm{h}}$ its wet weight;

- We pass the wet sample in an oven at a temperature of $105^{\circ}$ for 24 hours ;

- Determine the water content by weighing the difference (before and after drying).

Water content is given by the following expression:

$W(\%)=\frac{P_{h}-P_{s}}{P_{s}} \times 100$

With $\mathrm{P}_{\mathrm{h}}$ : wet weight of soil sample;

$P_{s}$ : dry weight of the soil sample.

\subsection{Statistical Analysis}

Analysis was performed using the SPSS program (SPSS $17)$, by analysis of variance $(p<0.05)$. In case of significance for interactions or between levels of the isolated factors, the DUCAN test was applied $(\mathrm{p}<0.05)$

\section{Results and Discussion}

The object set by our work is to study the compaction of soil by repeated traffic, the study of the effect of the weight of each tractor soil compaction and study the effect of time on the decompaction. These wheels are inflated to pressures 2 bars.

The characterization of soil compaction has been determinate by water retention characteristics and soil resistance to penetration.

The initial state of the field before passing the tractor was characterized by an initial series of measure. First, we measure the average water content over a depth of $10 \mathrm{~cm}$ that characterizes the initial state of soil (Table 2).

We measure the initial moisture at 0,10 and $20 \mathrm{~cm}$. These measurements show that the moisture decreases with the depth. This is decrease from $32 \%$ to $11 \%$, from 0 to $10 \mathrm{~cm}$ and 10 to $20 \mathrm{~cm}$.

Table 2: Moisture in soil

\begin{tabular}{|c|c|c|}
\hline Parcel & $\mathrm{H}_{\mathrm{p}}$ & Moisture (\%) \\
\hline \multirow{4}{*}{$P 1$} & $\mathrm{H}_{0}$ & 17.59 \\
\cline { 2 - 3 } & $\mathrm{H}_{10}$ & 11.98 \\
\cline { 2 - 3 } & $\mathrm{H}_{20}$ & 10.62 \\
\hline \multirow{4}{*}{$P 2$} & $\mathrm{H}_{0}$ & 16.96 \\
\cline { 2 - 3 } & $\mathrm{H}_{10}$ & 10.11 \\
\cline { 2 - 3 } & $\mathrm{H}_{20}$ & 9.35 \\
\hline \multirow{3}{*}{$P 3$} & $\mathrm{H}_{0}$ & 13.23 \\
\cline { 2 - 3 } & $\mathrm{H}_{10}$ & 8.96 \\
\cline { 2 - 3 } & $\mathrm{H}_{20}$ & 8.40 \\
\hline
\end{tabular}

Thus, after each pass of the tractor, a series of measures resistance to penetration, at the tracks of wheels is carried out to characterize the soil conditions.

\section{Parcel 1}

At the soil surface (parcel 1) at $[0 ; 5 \mathrm{~cm}]$, we see that the penetration resistance increases gradually after the initial state, passage of $\mathrm{T} 1$ and passage of $\mathrm{T} 2$, which shows the evolution of soil with the weight of the tractor. For example at a depth $5 \mathrm{~cm}$, compaction increases from $88 \%$ at the transition of the first tractor and $95 \%$ of the second tractor relative to the initial state. (Fig. 1)

The analysis of the results of Figure 2 shows that the resistance increases as a result of the passage of multiple tractor1. Measurements taken at $5 \mathrm{~cm}$ show that after a passage of tractor 1 , increasing the resistance to penetration exceeds $88 \%$ compared to the initial state, and the second passage shows an increase of $44 \%$ compared to the first passage.

This agrees with the results published in article for A. Elaoud and S. Chehaibi are valid (A. Elaoud et al., 2011). Examining the results of the penetration resistance (Figure 3) shows that the resistance decreases with time.

We compare the results of the penetration resistance to the initial state and after 20 days, this observation indicates a regression and reduction of the resistance that indicates the decrease compaction in time (decompaction by natural aeration soil in the time.)

An example to a depth of $10 \mathrm{~cm} \mathrm{Rp}=5.71 \mathrm{daN} / \mathrm{cm}^{2}$ in initial state and after 20 days $\mathrm{Rp}=2.67 \mathrm{daN} / \mathrm{cm}^{2}$ which shows a decrease of $53 \%$ in 20 days.

So, to see the effect of time after the first pass of the tractor made a series of measurements at the track wheel on the same day of the passage of the vehicle and another series of measurements after 20 days at inthe same trace. We note that over time the resistance to penetration increases, eg $10 \mathrm{~cm}$ Rp value increased from 2.96 to $3.12 \mathrm{daN} / \mathrm{cm}^{2}$.

\section{Parcel 2}

Early, figure 4 shows the effect of weight of on the soil in parcel 2 .

To a depth of $20 \mathrm{~cm}$, for example, there is a big difference between the penetration resistance at initial state $\left(1.51 \mathrm{daN} / \mathrm{cm}^{2}\right)$ after the first passage of tractor $\mathrm{T} 1\left(2.71 \mathrm{daN} / \mathrm{cm}^{2}\right)$ and after the first passage of tractor T2 (3.18 daN $\left./ \mathrm{cm}^{2}\right)$. This result shows an increase of $44 \%$ from initial state and that after the first pass to tractor1. Thus the increase between the effects of the first passage of tractor $\mathrm{T} 2$ is $53 \%$.

This shows that when you increase the mass of tractor of $36 \%(1900 \mathrm{~kg}$ to $1200 \mathrm{~kg})$, compaction in Parcel 2 increases of $15 \%$ at a depth of $20 \mathrm{~cm}$. 
Thus, on the second pass of the tractor T1 affect compaction of $10 \%$ compared to that of the first passage. (Fig. 5)

At first $10 \mathrm{~cm}$, it is proven that during the time the soil absorbs air and soil resistance regresses which shows a natural decompaction. (Fig. 6)

\section{Parcel 3}

At this plot, soil compaction is not particularly in depth verify. So for the second pass compaction is illustrated. The pressure of the wheels of the tractor (from the weight of the tractor) propagates towards a duct and soil compacting. (Fig 7 and 8)

These are (L.G. Wells et al, 1977), who showed that when the moisture content is less than 15\%, the penetration resistance increases with it. From Table 2, we see that the average moisture content decreased compared to baseline and remained below $17.59 \%$.

Also, our results are acceptable compared to the state of (H. Miyoshi, 1972), who notes that the penetration resistance of soil to $10 \mathrm{daN} / \mathrm{cm}^{2}$ was defined in Japan as the threshold for very severe constraint to rooting for a variety of cultures and on different soil types.

So we increased the number of passes is increased soil compaction. Thereby, the first passage density more the soil than the second.

For example at a depth of $5 \mathrm{~cm}$ can verify that the first passage affects compaction of $88 \%$ compared to the initial state and the second passage leads to compaction of $44 \%$ compared the first pass. These results are proved by A. Elaoud and S. Chehaibi.

Statistical analysis of measurements was based on the analysis of variance (ANOVA) through the software SPSS 17. The comparison between means was performed according to the Duncan test at $5 \%$.

Table 3 ANOVA results for soil resistance to penetration data. Parcel 1

\begin{tabular}{|c|c|c|}
\hline Source of variation & D.F. & M.S. \\
\hline Tractor & 1 & $14.90^{* *}$ \\
Passage & 1 & $1.41^{* *}$ \\
Depth & 15 & $17.66^{* *}$ \\
Error & 96 & 0.005 \\
\hline \multicolumn{2}{|c|}{${ }^{* *}$ significant at the 1\% level }
\end{tabular}

Statistical analysis of soil resistance to penetration data show highly significant effects $(\mathrm{P}<1 \%)$ of the tractor type, the tractor passage number and the depth on soil resistance (Table 3 ).

In parcel 1, the higher resistance corresponds to the second passage whereas the lowest occurs after the first passage of the tractor 1 .

Statistical comparison is performed at this level of penetration resistance in the number of passing parameter shows that the lowest intensity is performed after the first pass (table 4).

Table 4 Means comparisons of soil resistance to penetration as a function of the tractor passage number in parcel1

\begin{tabular}{|c|c|}
\hline Passage number & $\begin{array}{c}\text { Soil resistance to } \\
\text { penetration }\left(\mathrm{daN} / \mathrm{cm}^{2}\right)\end{array}$ \\
\hline $\begin{array}{c}\text { 0 (initial state without tractor } \\
\text { passage) }\end{array}$ & $4.53^{\mathrm{c}}$ \\
\hline 1 & $3.51^{\mathrm{a}}$ \\
\hline 2 & $3.75^{\mathrm{b}}$ \\
\hline
\end{tabular}

In parcel 2, statistical analysis of soil resistance to penetration data show highly significant effects ( $P$ $<1 \%$ ) of the higher resistance corresponds to the first passage whereas the lowest occurs after the second passage of the tractor 1 (table 5).

Table 5 ANOVA results for soil resistance to penetration data. Parcel2

\begin{tabular}{|c|c|c|}
\hline Source of variation & D.F. & M.S. \\
\hline Tractor & 1 & $1.97^{* *}$ \\
Passage & 2 & $1.21^{* *}$ \\
Depth & 14 & $10.22^{* *}$ \\
Error & 90 & 0.016 \\
\hline \multicolumn{2}{|c|}{$* *$ significant at the $1 \%$ level }
\end{tabular}

In parcel 3, statistical analysis of soil resistance to penetration data show highly significant effects ( $P$ $<1 \%$ ) of the higher resistance corresponds to the first passage whereas the lowest occurs after the second passage of the tractor (table 6).

Table 6. ANOVA results for soil resistance to penetration data in parcel3

\begin{tabular}{|c|c|c|}
\hline Source of variation & D.F. & M.S. \\
\hline Passage & 2 & $2.52^{* *}$ \\
Depth & 3 & $9.33^{* *}$ \\
Error & 90 & 0.016 \\
\hline \multicolumn{2}{|c|}{${ }^{* *}$ s significant at the 1\% level }
\end{tabular}

At the third parcel, statistical comparison is performed at this level of penetration resistance in the number of passing parameter shows that the lowest intensity is performed after initial state and after the first pass (table 7).

Considering the statistical analysis, it is clear that the results are highly significant mainly for the first tractor weight $1200 \mathrm{~kg}$ and for the number of passes is variable depending on the plot work and depth of not exceeding $15 \mathrm{~cm}$. 


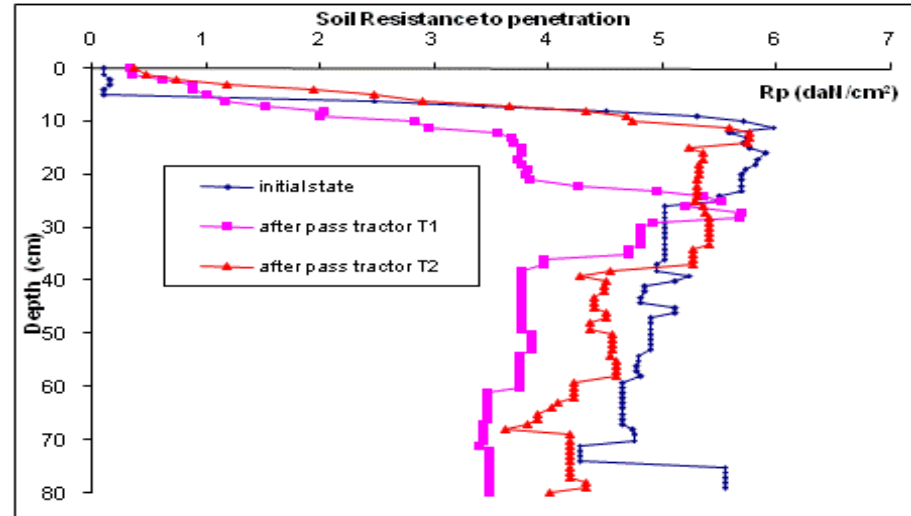

Figure 1 Measure of soil resistance to penetration after pass tractor 1 and 2 in parcel 1

Table 7 Means comparisons of soil resistance to penetration as a function of the tractor passage number in parcel 3

\begin{tabular}{|c|c|}
\hline Passage number & $\begin{array}{c}\text { Soil resistance to penetration } \\
\left(\mathrm{daN} / \mathrm{cm}^{2}\right)\end{array}$ \\
\hline 0 (initial state without tractor passage) & $1.15^{\mathrm{a}}$ \\
\hline 1 & $1.17^{\mathrm{a}}$ \\
$1^{\prime}$ & $1.5^{\mathrm{b}}$ \\
\hline 2 & $2.01^{\mathrm{c}}$ \\
\hline
\end{tabular}

$1^{\prime}$ after 20 days to first pass

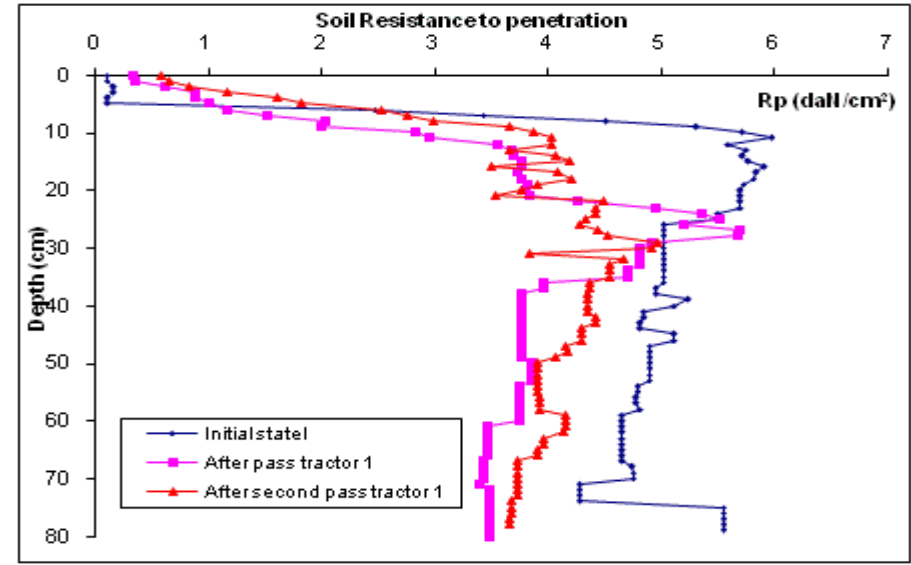

Figure 2. Measure of soil resistance to penetration after first and second pass of tractor 1 in parcel 1

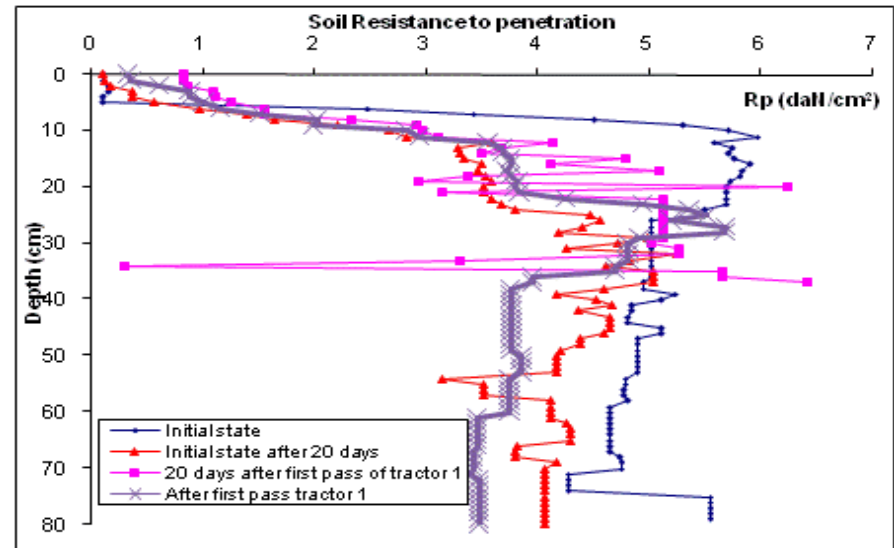

Figure 3. Measure of soil resistance to penetration function of time in parcel 1 


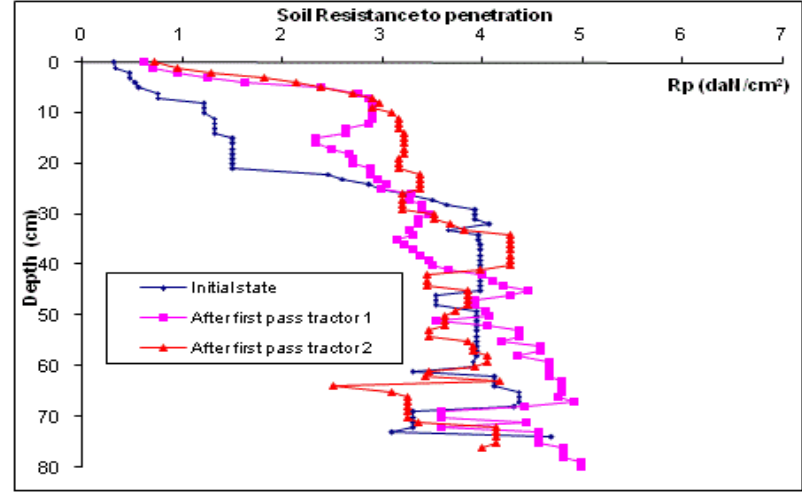

Figure 4 Measure of soil resistance to penetration after pass Tractor 1 and 2 in parcel 2

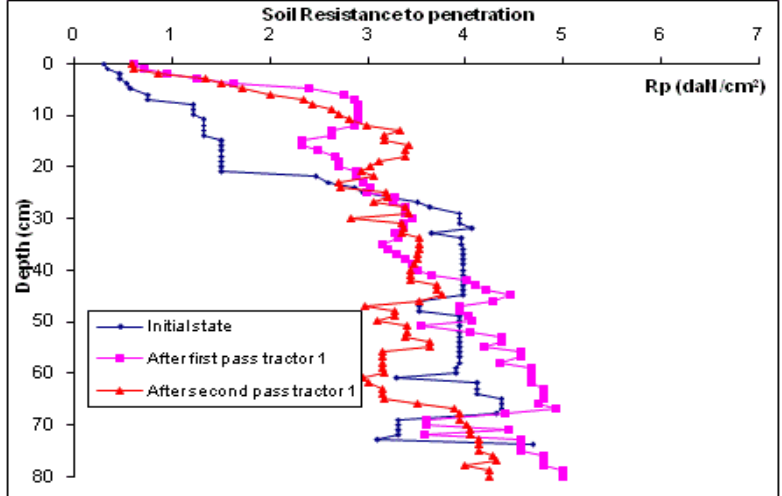

Figure 5. Measure of soil resistance to penetration after first and second pass of tractor 1 in parcel 2

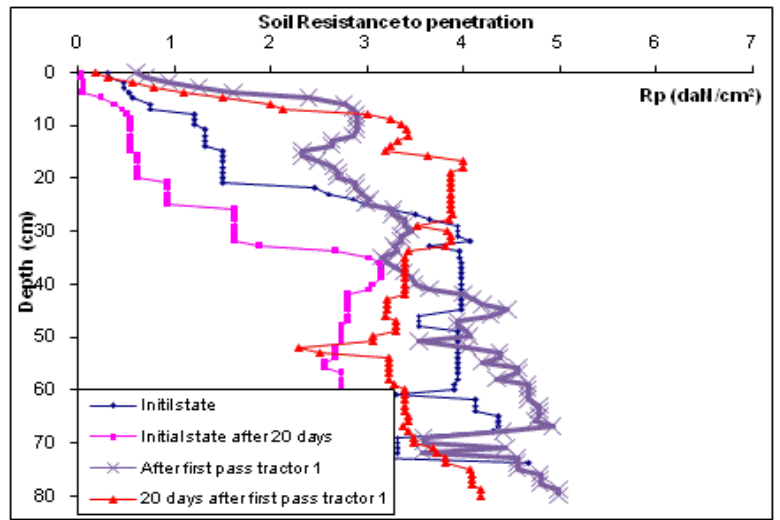

Figure 6. Measure of soil resistance to penetration function of time in parcel 2

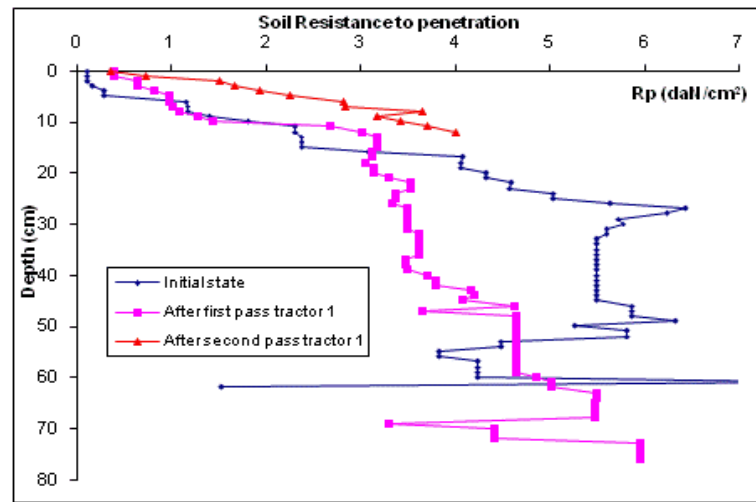

Figure 7. Measure of soil resistance to penetration after first and second pass of tractor 1 in parcel 3 


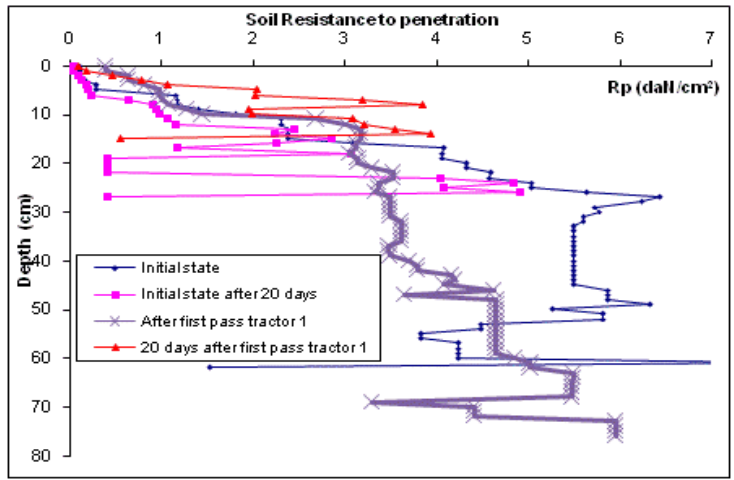

Figure 8 Measure of soil resistance to penetration function of time in parcel 3

\section{Conclusion}

We conducted an experimental study on the effect of the passage of two tractors. The time and the effect of passage number, showed the influence of the weight on the degree of soil compaction.

Indeed, the increase in weight on the ground transmits a steeper pressure that leads to a higher compaction. Therefore, to minimize the compaction of the soil is to be used as a small tractor, or to tire change more wider distribute the force of weight.

The average penetrometer profiles are closely related to the number of passage that proof that the first passage is most important at the impact of the settlement, it is for these reason it is necessary to choose the best condition in the first passage (content water, weight of vehicle, tire wheels) [A. Elaoud et al., 2011; J. Arvidsson et al., 2011].

The time parameter is measured in this work and shows that over time (a few days after compaction) soil decompact by natural effect (air absorption).

Thus many authors (M.A. Hamza et al., 2005; T. Keller, 2010)propose as a solution to degrease soil compaction the integration of organic matter that absorbs the phenomenon, and controls the number of passes is the best solution to avoid soil compaction (A. Elaoud et al., 2011), and finally optimisation choice of wheel and tire.

\section{References}

Vitlox O. \&Loyen S. (2002), Conséquences de la mécanisation sur la compaction du sol et l'infiltration de l'eau. Compte rendu de la journée d'étude: Erosion hydrique et coulées boueuses en Région Wallonne, pp. 45-58.

Pagliai M., Marsili A., Servadio P., Vignozzi N. \&Pellegrini S. (2003), Changes in some physical properties of a clay soil in central Italy following the passage of rubber trackedand wheeled tractors of meduim power.Soil Tillage Res. 73, 119-129.

Soane B. D. \& Van Ouwerkerk C. (1994), Soil compaction problems in word agriculture.Elseiver, Amsterdam, Netherlands.pp.1-22

Abou-Zied A.,Kushwaha R.L. \& Stilling D.S.D. (2004), Distributed soil displacement Associated with surface loading,ASAEpaper $\mathrm{n}^{\circ} 031024$. .

Batey T. (2009), Soil compaction and soil management. Soil Use and Management, 25: 335-345.

FAO. (2001), Systèmes de production et pauvreté. Améliorer les moyens d'existence des agriculteurs dans un monde en changement. Moyen-Orient et Afrique du Nord, 4 p.
Bonnefond P. (1970), L'introduction de la motorisation en agriculture traditionnelle, Cah. ORSTOM, n 4 , 21-33.

Håkansson L., Voorhees W.B. \& Riley H. (1988),Vehicle and wheel factors influencing soil compaction and crop response in different traffic regimes. Soil\& Tillage Res. 11, 239-282.

Chehaibi S., Hamza E., Pieters J. et Verschoore R. (2006), Analyse comparative du tassement du sol occasionné par les passages de deux types de tracteurs. Annales de l'INRGREF, n8,157-170.

Chehaibi S. et M'kacher I. (2008), Effets des passages multiples du tracteur sur le tassement et la perméabilité du sol. Revue des régions arides no21, pp. 875-880

Elaoud A., Chehaibi S. (2011), Soil compaction due to tractor traffic. Journal of Failure Analysis and Prevention JFAP - DOI 10.1007/s11668-011-9479-3, p539-545

Raghavan G.S.V., McKyes E. \& Taylor F.(1979), Soil compaction effects on soil productivity.Dept. Agric. Eng., Macdonald College of McGill Univ., St. Anne de Belleve, P. Q., Canada, 8 p

Botta G.F.,Tolon Becerra A. \&BelloraTourn F. (2009), Effect of the number of tractor passes on soil rut depth and compaction in two tillage regimes. Soil\& Tillage Res. 103, 381-386.

Vitlox 0. (1998), Répartition de la pression de contact des pneumatiques déterminée par la mesure de déformation du sol. Journée à thème conjointe de Pédologie et de Génie Rural, FUSAGxGembloux,pp.65-69.

Billot J.F., Aubineau M. \&Autelet R. (1993),Les matériels de travail du sol, semis et plantation. Paris: CEMAGREF/ITCF/TEC \& DOC, 384p

BengoughAG, Campbell DJ, O’Sullivan, MF.(2001), Penetrometer techniques in relation to soil compaction and root growth.Soil and Environmental Analysis.Physical Methods.2nd Edition. Eds. KA Smith, CE Mullins. pp. 377-403. Marcel Dekker: New York.

Lowery B, Morrison JE. (2002) Soil penetrometers and penetrability.Methods of Soil Analysis, Part 4, Physical Methods'.Eds. JH Dane, GC Topp pp. 363-388.Soil Science Society of America, Inc.: Madison, WI

Herrick JE, Jones TL(2002),A dynamic cone penetrometer for measuring soil penetration resistance. Soil Science Society of America Journal 66, 1320-1324

Kai C. (2008). Vers une approche hydro-mécanique du comportement des sols cultives: Experimentations et simulations. Thèse de doctorat à l'Institut des Sciences et industries du vivant et de l'environnement-Agro Paris Tech.

Wells L.G. \&Treesuwan 0. (1977).The response of various soil strength indices to changing water content.ASAE paper No. 771055, ASAE ST Joseph, MI 49085.

Miyoshi H.(1972) Effective layer for upland field from a view point of suitable soil condition for root development.Soil Sci. Plant Nut.,Vol $43, n^{\circ} 3,92-97$.

ArvidssonJ., WestlinH., Keller T., GilbertssonM. (2011), Rubber track systems for conventional tractors - Effects on soil compaction and traction.Soil \& Tillage Research 117, 103-107

Hamza M.A., \& Anderson W.K..(2005). Soil compaction in cropping systems a review of the nature, causes and possible solutions.Soil \& Tillage Research.82 pp 121-145

Keller T.,\&Håkansson I. (2010). Estimation of reference bulk density from soil particle size distribution and soil organic matter content. Geoderma 154, 398-406. 